\title{
Hidropsia fetal em neonato de cadela da raça Bulldog Francês - Relato de caso
}

Daniel Serafim de Andrade Rodrigues ${ }^{1 *}$, Brenda Lurian do Nascimento Medeiros ${ }^{1}$, Dalvan $\underline{\text { Fortaleza Alencar }}^{1}$, Dayse Andrade Barros ${ }^{1}$, Maykon Martins dos Santos ${ }^{1}$, Yago Gabriel da $\underline{\text { Silva Barbosa }}^{2}$, Marcelo Campos Rodrigues ${ }^{3}$, Francisco Lima Silva $^{3}$

${ }^{I}$ Graduando em Medicina Veterinária, Universidade Federal do Piauí, Teresina.

${ }^{2}$ Residente em Clínica Médica de Cães e Gatos, Universidade Federal do Piauí, Teresina.

${ }^{3}$ Professor do Departamento de Clínica e Cirurgia Veterinária, Universidade Federal do Piauí, Teresina.

*Autor para correspondência, E-mail: danielserafimvet@gmail.com

RESUMO. A hidropsia fetal é uma patologia caracterizada pelo acúmulo de líquido anormal no espaço extravascular do feto, causando edema generalizado no tecido subcutâneo e acúmulo de líquidos nas cavidades. Esta patologia provoca o aumento exagerado no tamanho do feto, resultando em distocia obstrutiva durante o parto. Cães braquicefálicos como o Bulldog Francês possuem maior prevalência em casos de hidropsia fetal, o que resulta no aumento dos índices de perdas fetais e cesarianas. Objetiva-se relatar um caso de hidropsia fetal em um neonato de cadela da raça Bulldog Francês atendido em uma clínica particular na cidade de Teresina-PI.

Palavras chave: Hidropsia fetal, neonato, edema.

\section{Fetal hydrops in newborn of bitch breed French Bulldog - Case report}

\begin{abstract}
Fetal hydrops is a disorder characterized by abnormal accumulation of fluid in the extravascular space of the fetus, causing generalized edema in subcutaneous tissue and fluid buildup in the cavities. This condition causes excessive increase in the size of the fetus resulting in obstructive dystocia during delivery. Brachycephalic dogs as the French Bulldog have a higher prevalence in cases of fetal hydrops, which results in increased fetal loss and cesarean rates. It aims to report a case of fetal hydrops in a French Bulldog breed of dog neonates treated at a private clinic in the city of Teresina-PI.
\end{abstract}

Keywords: Fetal hydrops, newborn, edema.

\section{Introdução}

A hidropsia fetal é caracterizada pelo acúmulo de líquido anormal no espaço extravascular do feto, causando edema subcutâneo generalizado (anasarca) e coleções em quantidade variável nas cavidades peritoneal, pleural e pericárdica (Toniollo \& Vicente, 2003; Sorribas, 2006).

Segundo Toniollo \& Vicente (2003) a hidropsia fetal pode ser classificada em três tipos: efusão peritoneal, denominada ascite; anasarca ou Síndrome do filhote Morsa, que é o edema generalizado do tecido subcutâneo e hidrocefalia, que é um acúmulo de líquido no sistema ventricular ou entre o encéfalo; e a duramater comumente encontrado em suínos, bezerros e mais raramente em cães.

A hidropsia fetal provoca o aumento exagerado no tamanho do feto, resultando em distocia obstrutiva durante o parto (Nelson \& Couto, 2015). As raças Bulldog Inglês, Pug, Boston Terrier e Bulldog Francês possuem maior incidência para hidropsia fetal, resultando no aumento dos índices de perdas fetais e cesarianas (Sorribas, 2006).

A condição pode ser detectada ao exame ultrassonográfico gestacional sendo caracterizada pelo aumento da espessura subcutânea do feto representado por halo anecogênico entre a pele e a musculatura (Assis et al., 2013). 
A hidropisia do tipo anasarca, em animais, é descrita como sendo causada por genes autossômicos recessivos e anomalias hipofisárias que resultam em edema generalizado do subcutâneo, excesso de líquido nas cavidades peritoneal e pleural, dilatação dos anéis umbilical e inguinal, bem como hidrocele e edema das membranas fetais Os fetos acometidos chegam a termo; porém, devido ao excesso de líquido no tecido subcutâneo, normalmente causam distocias, sendo necessária, nestes casos, uma intervenção cirúrgica através de cesariana ( et al., 2012).

\section{Descrição do caso}

Foi atendido em um clínica veterinária da cidade de Teresina, (Estado de Piauí - Brasil), uma cadela da raça Bulldog Francês, dois anos de idade com peso de $11,5 \mathrm{~kg}$ e prenhez de 60 dias. $\mathrm{O}$ proprietário relatava que a cadela tinha entrado em trabalho de parto há mais de 6 horas e não conseguia expulsar os fetos. Ao exame de ultrassonografia foi observado um feto com tamanho aumentado e outro inviável em um total de cinco; sendo solicitada a realização de cesariana.

Ao se realizar cirurgia, como já diagnosticada ao exame de ultrassom, havia a presença de um feto aumentado de tamanho, outro inviável e três viáveis. O primeiro filhote, que estava em contato com a cérvix uterina, apresentava-se edematoso e exageradamente aumentado de tamanho (Figura

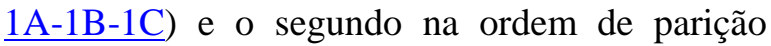
apresenta-se em tamanho normal, sem alterações, porém natimorto (Figura 1C).

O filhote edematoso veio a óbito nos primeiros minutos de vida, sendo posteriormente realizado a necropsia, onde foi observado edema generalizado nos tecidos (Figura 2), efusão pleural (Figura 3) e efusão peritoneal. Após necropsia, o filhote foi diagnosticado como um caso de hidropsia fetal do tipo anasarca.
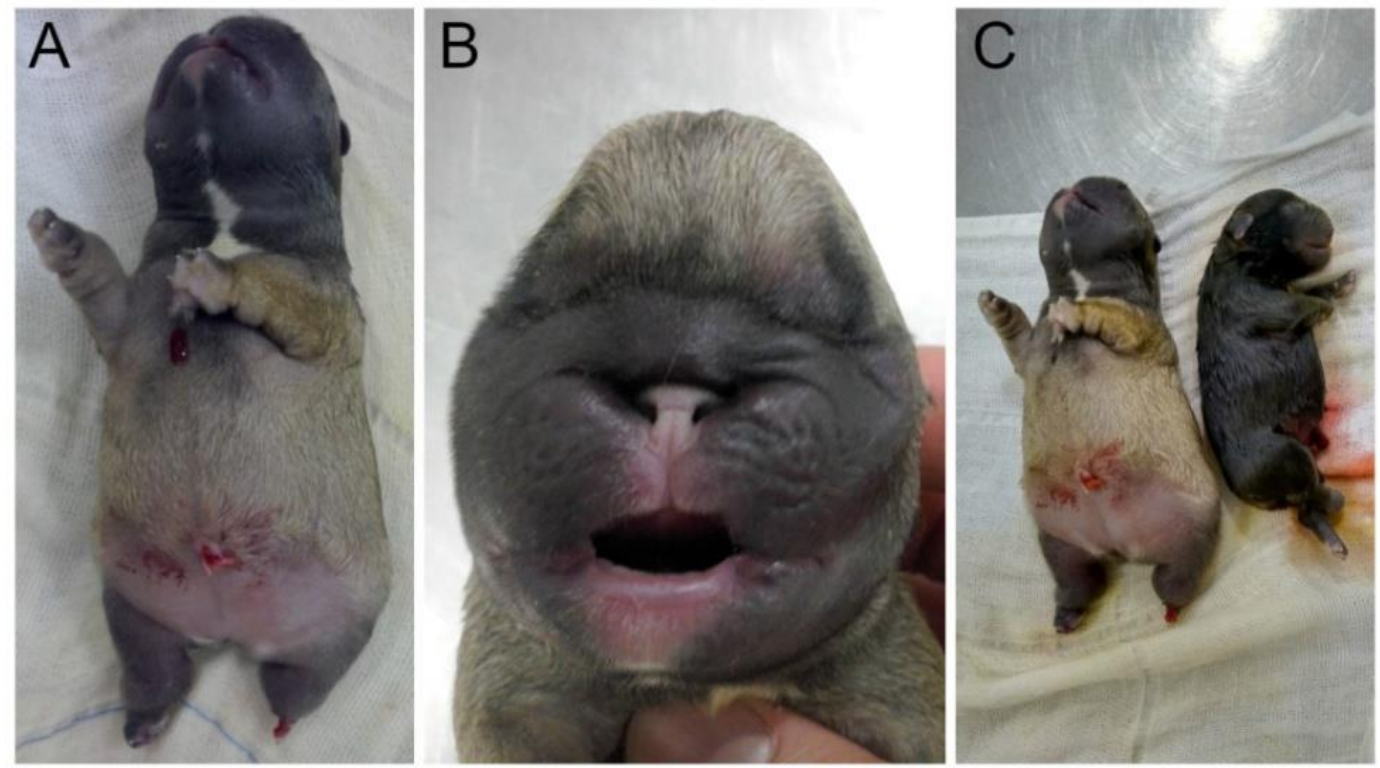

Figura 1. Filhote hidrópico apresentando edema generalizado e aumento de tamanho (A, B). Comparação de tamanho entre o filhote hidrópico e o filhote natimorto de tamanho normal (C).

\section{Discussão}

As características ultrassonográficas dos fetos, durante a gestação, indicam a condição dos futuros neonatos (Assis et al., 2013) e auxiliam na escolha do procedimento, clínico ou cirúrgico, fato ocorrido no presente caso.

O primeiro filhote, que estava em contato com a cérvix uterina, apresentava-se edematoso e exageradamente aumentado de tamanho e o segundo na ordem de parição, apresenta-se em

tamanho normal, sem alterações congênitas, porém natimorto. Ao comparar um neonato de tamanho normal com o neonato hidrópico observou-se a desproporção de tamanho entre ambos, estando em acordo com o relatado por Silva et al. (2012), ao relatarem que os fetos acometidos pela hidropsia do tipo anasarca apresentam excesso de líquido no tecido subcutâneo. 

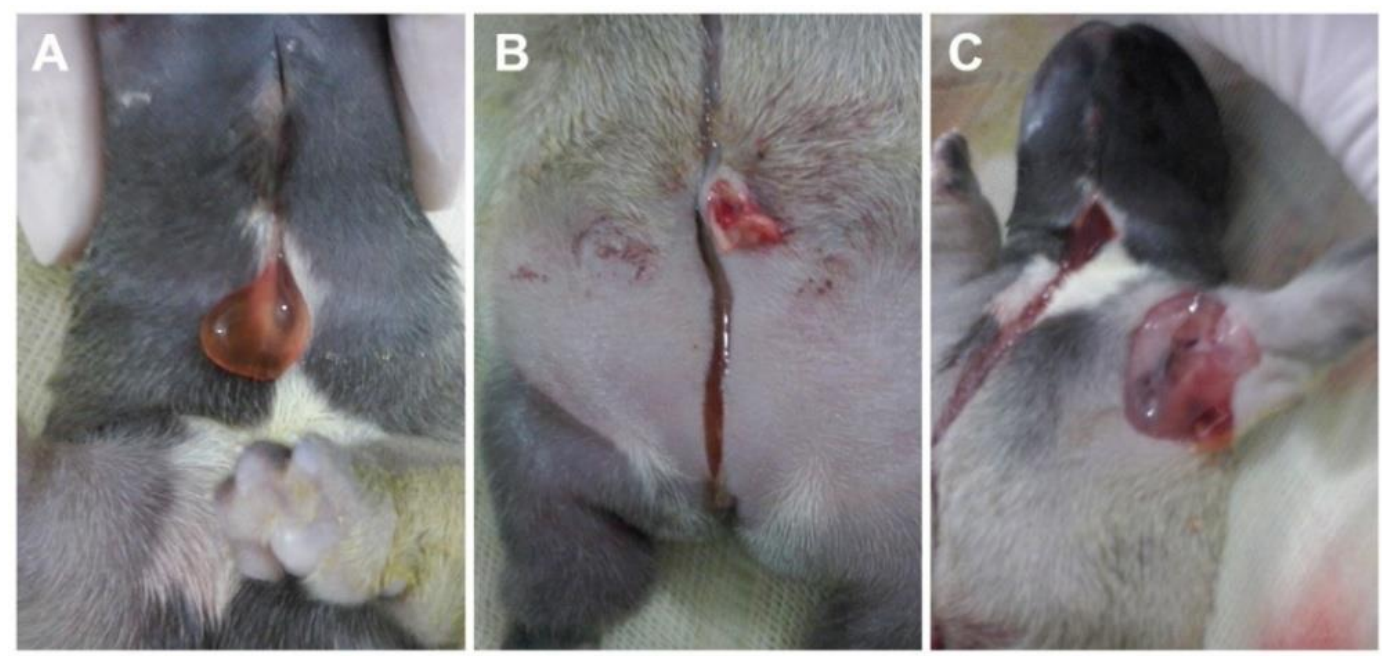

Figura 2. Filhote ao exame necroscópico, apresentando edema de subcutâneo generalizado com efusão de líquido ao corte. Porção ventral do pescoço (A), Abdômen (B) e região axilar (C).

Assim como o observado por Silva et al. (2012) o filhote hidrópico veio a óbito nos primeiros minutos após o nascimento. Foi realizada a necropsia, onde conforme o descrito Toniollo \& Vicente (2003), Sorribas (2006) e Silva et al. (2012) foi encontrado edema generalizado no tecido subcutâneo, efusão pleural e efusão peritoneal.

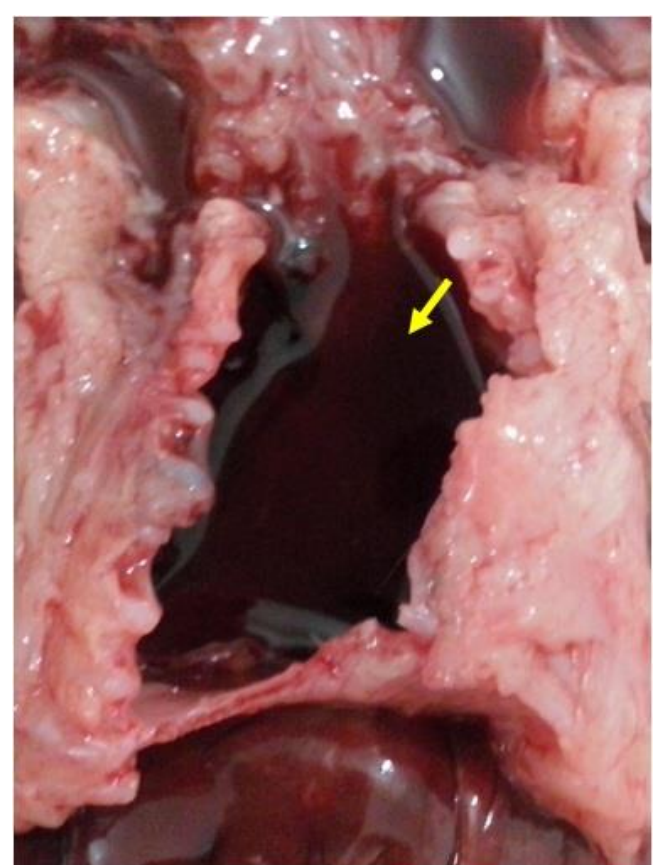

Figura 3. Cavidade torácica ao exame necroscópico após remoção dos pulmões e coração, demonstrando acúmulo de líquido (seta).

Conforme Nelson \& Couto (2015), a hidropsia fetal provoca o aumento exagerado no tamanho do feto, resultando em distocia obstrutiva durante o parto. Assim sendo, verificou-se que a inviabilidade do feto edematoso resultou na distocia durante o parto por obstrução do canal da cérvix, o que ocasionou também no óbito do feto subsequente.

\section{Conclusão}

A hidropsia fetal pode resultar em distocia obstrutiva durante o parto, devido ao aumento exagerado no tamanho do feto, podendo ocorrer comprometimento da vida da ninhada e da cadela gestante. Para tanto, é necessário o acompanhamento gestacional da cadela através de ultrassonografia, a fim de diagnosticar qualquer complicação nos neonatos do desenvolvimento até o nascimento.

\section{Referências Bibliográficas}

Assis, A. R., Martin, C. M., Cantadori, D. T., Paiva, F. D. \& Tabosa, M. S. P. (2013). Diagnóstico ultrassonográfico de hidropsia fetal em gestações consecutivas associadas a óbito perinatal das ninhadas em cadela bulldog inglês. Anais do $34^{\circ}$ Congresso Nacional da Anclivepa. Acta Veterinaria Brasilica, 7, Supl. 1.

Nelson, R. W. \& Couto, C. G. (2015). Medicina interna de pequenos animais. 5 ed. Rio de Janeiro: Elsevier, 1474 p.

Silva, T. M., Zakimi, R. S., Garcia, P. D., Thomé, H. E., Lorenço, M. L. G. \& Alves, J. D. S. (2012). Diagnóstico ultrassonográfico de hidropisia fetal intrauterino - relato de caso. Revista de Educação Continuada em 
Medicina Veterinária e Zootecnia do CRMV, 10, 26-31.

Sorribas, C. E. (2006). Atlas de Reprodução Canina: São Paulo. 348p.

Toniollo, G. H. \& Vicente, W. R. R. (2003). Manual de obstetrícia veterinária. São Paulo: Varela, 77-84.
Recebido em Fevereiro 27, 2016

Aceito em Março 30, 2016

License information: This is an open-access article distributed under the terms of the Creative Commons Attribution License, which permits unrestricted use, distribution, and reproduction in any medium, provided the original work is properly cited 